\title{
Histology-specific risks in testicular cancer in immigrants to Sweden
}

\author{
Kari Hemminki $i^{1,2,3}$, Seyed Mohsen Mousavi ${ }^{1}$, Andreas Brandt ${ }^{1}$, \\ Jianguang $\mathrm{Ji}^{2}$ and Jan Sundquist ${ }^{2,4}$
}

\author{
${ }^{1}$ Division of Molecular Genetic Epidemiology, German Cancer Research Centre (DKFZ), 69120 Heidelberg, Germany \\ ${ }^{2}$ Center for Primary Care Research, Lund University, Malmö, Sweden \\ ${ }^{3}$ Karolinska Institute, Center for Family and Community Medicine, Huddinge, Sweden \\ ${ }^{4}$ Stanford Prevention Research Center, Stanford University School of Medicine, Stanford, California, USA \\ (Correspondence should be addressed to K Hemminki at Division of Molecular Genetic Epidemiology, German Cancer Research \\ Centre (DKFZ); Email: k.hemminki@dkfz.de)
}

\begin{abstract}
The changes of cancer incidence upon immigration have been used as an estimator of environmental influence on cancer risk. The previous immigrant studies have indicated that the origins of testicular cancer are at an early age in life, probably in the intrauterine period. We wanted to reexamine the critical periods on histology-specific testicular cancer in sons of immigrants to Sweden. We used the nationwide Swedish Family-Cancer Database to calculate standardized incidence ratios (SIRs) for testicular cancer in sons of parents immigrating to Sweden from low- and high-risk countries compared with the native Swedes. Among the large immigrant groups, the SIRs for sons of two Finnish and Asian parents were decreased if the sons were born outside Sweden. The sons of a Danish immigrant couple showed an increased risk of testicular cancer. The changes in SIR were most systematic for seminoma. The present patterns of testicular cancer risk among sons of immigrants point to the early environmental risk factors, which influence the risk probably after the intrauterine period. These factors appear to influence seminoma risk in a more enduring way than they influence non-seminoma.
\end{abstract}

Endocrine-Related Cancer (2010) 17 329-334

\section{Introduction}

Testicular cancer is the most frequently occurring cancer in young white men aged 15-35 years. The incidence of testicular cancer has increased in many countries, including Sweden, for unknown reasons (Richiardi et al. 2004, Boyle \& Levin 2008). Testicular cancers are predominantly germ cell tumors of two main types, seminomas and non-seminomas; the later include teratomas with somatic differentiation and undifferentiated embryonal tumors (Eble et al. 2003). However, about one half of germ cell tumors of the testis contain multiple histological types, and the remainder contains a single histological type (Eble et al. 2003). Similar incidence trends in seminoma and non-seminoma have been suggested to imply sharing of etiological factors between the histological types (Bray et al. 2006). The known risk factors of testicular cancer include undescended testis (cryptorchidism), testicular dysfunction, perinatal factors, prior history of cancer in one testis (the opposite testis is at increased risk), and family history of testicular cancer, as reviewed (Eble et al. 2003, Boyle \& Levin 2008). The first-generation immigrants to Sweden show generally a decreased risk of testicular cancer compared with the natives, but this difference tends to disappear in the next generation born in Sweden (Hemminki \& Li 2002b, Hemminki et al. 2002). The effect was marked among the sons of the Finnish immigrants, whose risk was doubled compared with their fathers (Hemminki \& Li 2002a, Ekbom et al. 2003, Montgomery et al. 2005). Among the sons of the Danish immigrants, coming from a high-risk country, an equally large but opposite change took place (Hemminki \& Li 2002a). Low testicular cancer risks among immigrants were observed in Denmark, suggested to implicate the early life or the in utero period (Myrup et al. 2008).

Sweden is an excellent country to study cancer experience of the immigrants because of a uniform 
cancer registration and health care system and the large number of immigrants from practically around the world: in the Family-Cancer Database with 11.8 million individuals, some $15 \%$ are foreign born (Hemminki et al. 2009). In the present paper, we examine risks of histology-specific testicular cancer in offspring immigrants to Sweden according to their and their parents' birth country in order to pinpoint the critical factors for the incidence change.

\section{Subjects and methods}

The Swedish Family-Cancer Database was first assembled from the national databases in 1996, and since then it has been periodically updated (Hemminki et al. 2001). The Database contains data on those born in Sweden since 1932 with their biological parents, and additionally data on immigrants are included. This Database is the largest in the world on familial cancer, and its updated version (2008, VIII) which has been supplied with longitudinal demographic and socioeconomic data from each national census of 1960 , 1970, 1980, 1990, and 2000 has been used for the present study (Hemminki et al. 2009).

Immigrants were defined according to their birth country. First-generation immigrants were defined as those without identified parents in the Database. Follow-up was started on the date of immigration or January 1, 1958, whichever came latest; if the date of immigration was missing, follow-up was started on the first year in which the immigrant was present at a census. Follow-up was terminated on diagnosis of cancer, death, emigration, last year presence at the census, or the closing date of our study, December 31, 2006. Standardized incidence ratios (SIRs) were calculated as the ratio of observed $(\mathrm{O})$ to expected (E) number of cases. The expected numbers were calculated from 5-year age group, sex, period (10-year bands from 1958 to 2006), and tumor type-specific standard incidence rates. Cancer incidence for the native Swedish populations was used as reference. Confidence intervals (95\% CI) were calculated assuming a Poisson distribution. SAS software ver.9.1 was used for data analysis.

\section{Results}

The Family-Cancer Database covered years 1958-2006 from the Swedish Cancer Registry, and it included 6833 testicular cancers in the native Swedish reference population. Table 1 shows the risk for testicular cancer in the first-generation immigrants.

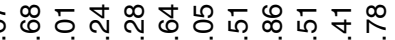

o n n

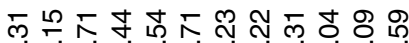

$0.000000 \%$

ஊ

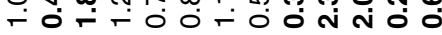

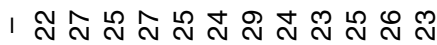

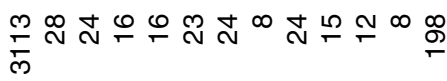
$>\frac{\Gamma}{\Gamma}$

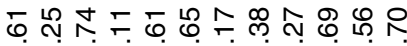
○े

లิ O-

๓

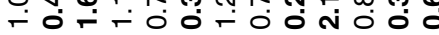

।

옹

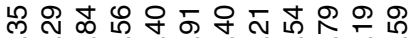

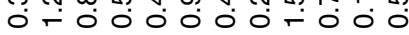

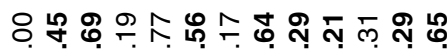

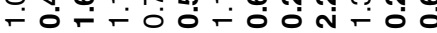

ల్లో 8 \&

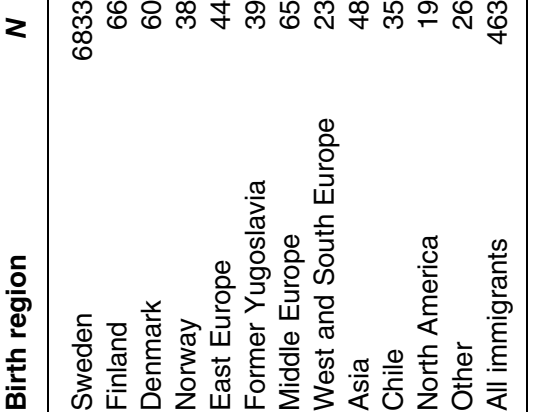




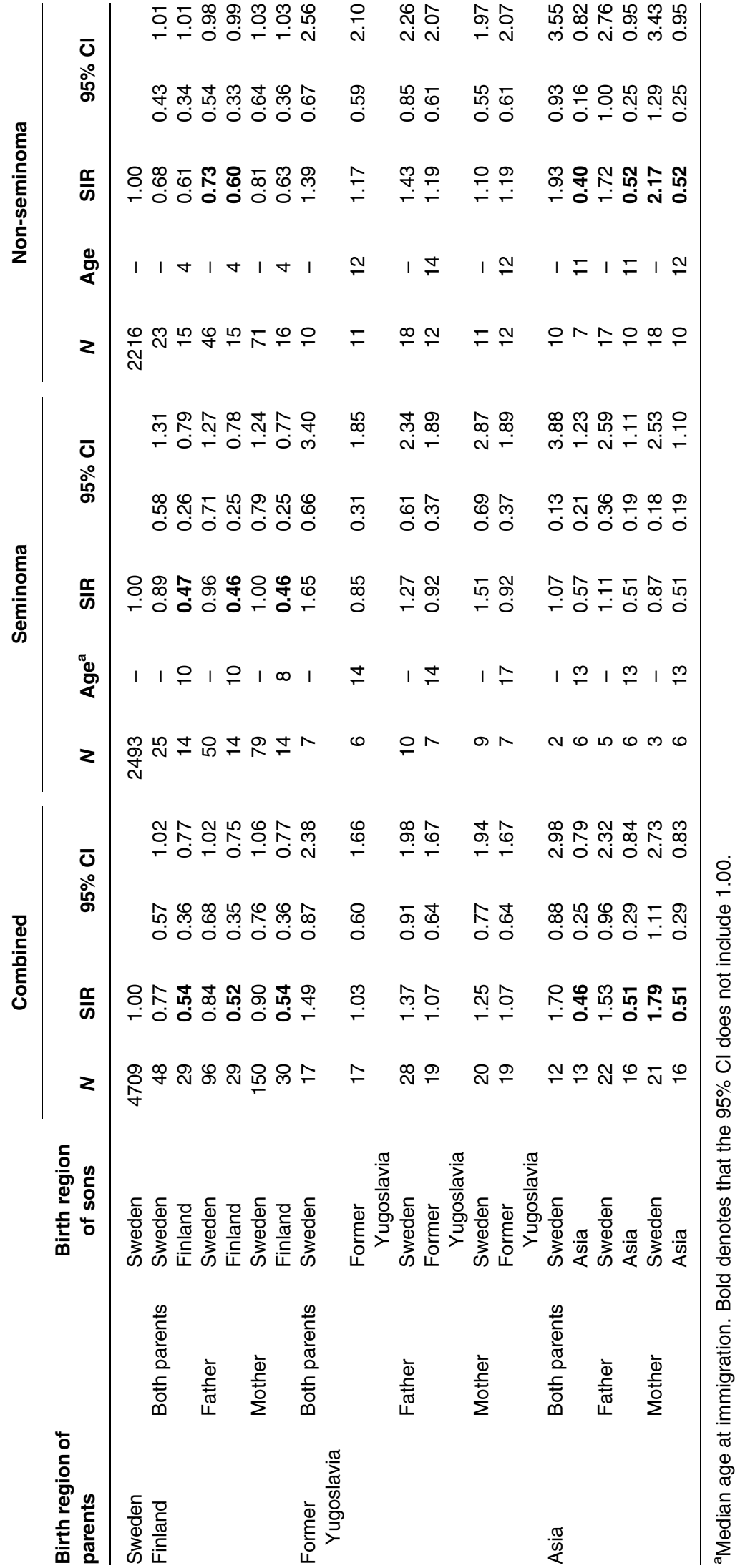


Significantly decreased risks for all testicular cancer were observed for Finns (SIR 0.45), former Yugoslavians (0.56), Western and Southern Europeans (0.29), Asians (0.29), and others (0.29). Only Danish (1.69) and Chilean (2.21) immigrants showed increased risks. The observed overall changes were seen for both seminomas and non-seminomas, with the exception of former Yugoslavians with a risk for seminoma only and North Americans showing an increased risk of non-seminoma (2.01). For seminoma and non-seminoma, we show the median age at immigration which varied from 22 to 30 years.

The risks were analyzed for sons of the firstgeneration immigrants by considering the sons' and their parents' birth region. Table 2 covered three regions of low risk for the immigrant fathers of Table 1. Considering the combined histological types, the sons of two Finnish immigrants had an SIR of 0.77 (95\% CIs 0.57-1.02) when they were born in Sweden compared with an SIR of 0.54 when they were born in Finland. The results were essentially identical for the combined histologies and seminoma, even if only the father or the mother was born in Finland. For seminoma, there was no risk if the sons were born in Sweden. For non-seminoma, all SIRs were of borderline significance, and the SIRs were only marginally higher if the birth county was Sweden instead of Finland. For the sons of the Yugoslavian immigrants, none of the SIRs were significant. For the sons of the Asian immigrants, the risks were decreased for the combined histologies and for non-seminomas when the sons were born in Asia, but they exceeded the Swedish rates when the sons were born in Sweden; notably the Sweden-born sons of the Asian mothers showed an increased risk of non-seminoma (2.17). Seminomas tended to be decreased for the sons of the Asia-born parents, but the case numbers were few in this relatively young immigrant population. The median ages at immigration, shown for seminoma and non-seminoma, were between 4 and 10 years for the sons of the Finnish immigrants, and between 11 and 17 years for the sons of Yugoslavian and Asian immigrants.

The risks for the sons of the Danish and Chilean immigrants are shown in Table 3. For the Danish immigrant sons, the risk for the combined histologies and for seminoma were increased but only if the sons were born in Denmark. No significant increases were observed for the Sweden-born sons of the Danish immigrants for the combined histologies or non-seminoma; however, all these SIRs were higher than the unity. No significant differences were observed for the sons of the Chilean immigrants.

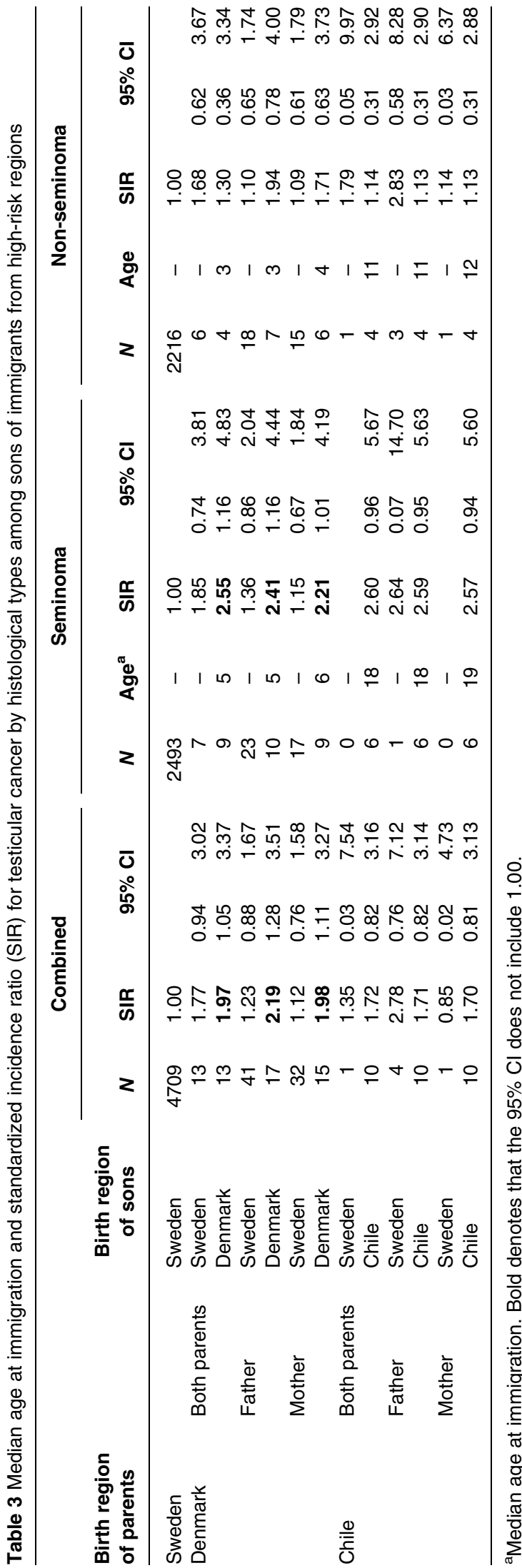


The median age at immigration of the sons of the Danish immigrants varied between 3 and 6 years, compared with 11 to 19 years for the sons of Chilean immigrants.

\section{Discussion}

Many immigrants have arrived as young couples (median age around 24 years) to Sweden, whereby their Sweden-born children have a completely indigenous genotype of their parental ethnicity (Hemminki et al. 2009). The results of the previous publications led us to conclude that the childhood environment, rather than genotype, is very important in setting the individual's cancer destiny (Hemminki \& Li 2002b, Hemminki et al. 2002). Many immigrant groups originate from countries with no cancer registration, and, hence, the Swedish data may provide estimates on the indigenous cancer rates. Some surprising findings have been, for example, the testicular cancer rates in Chileans which are among the highest in the world. However, the overall testicular cancer rates recorded in the first-generation immigrants have agreed with pattern reported in the GLOBOCAN cancer maps (Ferlay et al. 2001, Boyle \& Levin 2008), as also seen in Table 1. Caution is, however, warranted because the highest incidence of non-seminoma (25 years) coincides with the median immigration age of the first-generation immigrants; the peak incidence of seminoma is around 35 years (Hemminki \& $\mathrm{Li}$ 2004). People with a diagnosed cancer are unlikely to emigrate to the same degree as their healthy country mates. For the children of immigrants who immigrated at a young age, the selection is not likely to be important; thus our main focus was on sons of the firstgeneration immigrants. Among second-generation seminoma patients, the highest median age at immigration, 18-19 years, was recoded for Chileans, while among non-seminoma patients, former Yugoslavians showed the highest median immigration age of 12-14 years.

The main conclusion of the present study was that among the large immigrant groups Finns, Asians, and Danes, the protection or risk observed in the firstgeneration remained in sons who were born in the region of origin, but the changes disappeared in sons born in Sweden. Whether only the mother or the father was the immigrant did not change the conclusion, but very few children in such mixed marriages were born outside Sweden. For Chileans, the number of affected sons was small to be conclusive. The sons of Yugoslavs did not show a clear risk pattern even though the case numbers were reasonable. The rates for the sons born in the former Yugoslavia were higher than the Swedish rates, thus apparently higher than the rates in their immigrant fathers. The median time since immigration was 12 years, i.e. about 1994. Whether the local conflicts and refuge status influence the risks in the young sons remains a possible explanation. Overall, the present data do not point to in utero effects, because the in utero environment may be assumed to be largely similar whether the couples are having their children inside or outside Sweden, in the neighboring countries of Finland or Denmark. Rather, the early life environment of the sons predicates the risk. It is likely that the compatriot families keep some of their traditions in child raising, and these are not likely to change drastically upon immigration. Thus, the factors that tend to unify the testicular cancer rates of the immigrants with the Swedish level are probably among the assimilating guidelines and practices related to diet supplementation, nutrition, child care, and school start. However, the present case numbers are small and the importance of the early childhood and youth environment needs to be confirmed in other settings.

The question about histology remains somewhat unambiguous because of the small numbers in the younger immigrant populations of Yugoslavians, Asian, and Chileans. Among the sons of the Finns and Danes, born outside Sweden, the largest deviations from the Swedish histological patterns were observed for seminoma. This suggests that the origins of seminoma are more stably imprinted than those of non-seminoma, even though the peak incidence for seminoma is 10 years later than that of non-seminoma (Hemminki \& Li 2004).

In summary, the present data on the patterns of testicular cancer risk among sons of immigrants appears to implicate the early environmental risk factors, which influence the risk probably after the intrauterine period. These factors appear to influence seminoma risk in a more enduring way than they influence non-seminoma.

\section{Declaration of interest}

The authors declare that there is no conflict of interest that could be perceived as prejudicing the impartiality of the research reported.

\section{Funding}

Supported by Deutsche Krebshilfe, the Swedish Cancer Society and the Swedish Council for Working Life and Social Research. 


\section{Acknowledgements}

The Family-Cancer Database was created by linking registers maintained at Statistics Sweden and the Swedish Cancer Registry.

\section{References}

Boyle P \& Levin B 2008 In World Cancer Report 2008. Lyon: IARC Press.

Bray F, Richiardi L, Ekbom A, Forman D, Pukkala E, Cuninkova M \& Moller H 2006 Do testicular seminoma and nonseminoma share the same etiology? Evidence from an age-period-cohort analysis of incidence trends in eight European countries Cancer Epidemiology, Biomarkers and Prevention 15 652-658.

Eble J, Sauter G, Epstein J \& Sesterhenn I 2003 In Tumors of the Urinary System and Male Genital Organs. Lyon: IARC Press.

Ekbom A, Richiardi L, Akre O, Montgomery SM \& Sparen P 2003 Age at immigration and duration of stay in relation to risk for testicular cancer among Finnish immigrants in Sweden. Journal of the National Cancer Institute 95 1238-1240.

Ferlay J, Bray F, Pisani P \& Parkin DM 2001 In GLOBOCAN 2000. Cancer Incidence, Mortality and Prevalence Worldwide. Lyon: IARC Press.

Hemminki K \& Li X $2002 a$ Cancer risk in Nordic immigrants and their offspring in Sweden. European Journal of Cancer 38 2428-2434.
Hemminki K \& Li X 2002b Cancer risks in secondgeneration immigrants to Sweden. International Journal of Cancer 99 229-237.

Hemminki K \& Li X 2004 Familial risk in testicular cancer as a clue to a heritable and environmental aetiology. British Journal of Cancer 90 1765-1770.

Hemminki K, Li X, Plna K, Granström C \& Vaittinen P 2001 The nation-wide Swedish family-cancer database: updated structure and familial rates. Acta Oncologica 40 772-777.

Hemminki K, Li X \& Czene K 2002 Cancer risks in first generation immigrants to Sweden. International Journal of Cancer 99 218-228.

Hemminki K, Ji J, Brandt A, Mousavi SM \& Sundquist J 2009 The Swedish Family-Cancer Database 2009: prospects for histology-specific and immigrant studies. International Journal of Cancer [in press].

Montgomery SM, Granath F, Ehlin A, Sparen P \& Ekbom A 2005 Germ-cell testicular cancer in offspring of Finnish immigrants to Sweden. Cancer Epidemiology, Biomarkers and Prevention 14 280-282.

Myrup C, Westergaard T, Schnack T, Oudin A, Ritz C, Wohlfahrt J \& Melbye M 2008 Testicular cancer risk in first- and second-generation immigrants to Denmark. Journal of the National Cancer Institute 100 41-47.

Richiardi L, Bellocco R, Adami HO, Torrang A, Barlow L, Hakulinen T, Rahu M, Stengrevics A, Storm H, Tretli S et al. 2004 Testicular cancer incidence in eight northern European countries: secular and recent trends. Cancer Epidemiology, Biomarkers and Prevention 13 2157-2166. 